\title{
Test rig for welding diamond wires into a loop
}

\author{
Ricardo Knoblauch $^{1}$, Claudio Abilio da Silveira ${ }^{1}$, João Eduardo Souza de Campos ${ }^{1}$ \\ Walter Lindolfo Weingaertner ${ }^{1}$, Fabio Antonio Xavier ${ }^{1}$, Konrad Wegener ${ }^{2}$
}

\begin{abstract}
The multi-wire sawing of silicon using a steel wire coated with diamond grits (diamond wire) is an important process in the semiconductor and photovoltaic industry. The cut is performed in the industry by pushing a silicon ingot against a diamond wire web that moves in a pilgrim-mode (forwards and backwards). As the cut direction and cutting speed of the wire change multiple times during the operation, it is very difficult to perform a proper investigation of the cutting process. In order to study the multi-wire sawing of monocrystalline silicon (mono-Si), a new experimental setup has been proposed. Based on literature research and industry know-how, the main features necessary for the proposed wafering test rig have been defined as follows: i) use of a short wire looped segment; ii) cut with controllable constant wire speed and iii) permit to track specific diamond grains after each cut for wear analysis. In order to fulfill these prerequisites, the first step is to butt-weld diamond wires into looped shape in a wire outer diameter range of $200<0 D<500 \mu \mathrm{m}$. The adopted solution is a resistance butt-welding device. In this device, the wire ends are clamped with tight alignment. By the application of electric current through the wire ends interface, heat is generated by Joule effect and the incandescent heated material is pressed together with controlled force, creating the joint. After the joint is formed, a lower electric current heats the joint for a tempering procedure to increase material ductility. The conceptual design of the device is presented, followed by details of the actual device. Butt-welds of diamond wires with $O D=200 \mu \mathrm{m}$ and $350 \mu \mathrm{m}$ were successfully done, resulting in welded joints with good alignment, and sufficient tensile strength for the endless wire sawing application.
\end{abstract}

Keywords - diamond wire, endless wire saw, butt-welding, resistance welding, wafering

\section{Introduction}

The multi-wire technology is the process responsible for slicing the silicon ( $\mathrm{Si}$ ) ingots into wafers. The cost to produce Si wafers accounts for approximately $30-40 \%$ of the total solar cell fabrication cost, and about $80 \%$ of the world's solar cells in photovoltaic industry are currently fabricated using mono$\mathrm{Si}$ [1]-[4]. Hence, the multi-wire sawing of silicon ingots is an important subject to be investigated, especially when it comes to the idea of reducing production costs to make this energy production more accessible.

Ricardo Knoblauch ${ }^{1}$ ${ }^{1}$ Precision Engineering Laboratory, LMP
Universidade Federal de Santa Catarina, UFSC
Brazil

${ }^{2}$ Institute of Machine Tools and Manufacturing, IWF Swiss Federal Institute of Technology, ETH Zurich Switzerland
A schematic of the multi-wire sawing technology is shown Fig. 1. A single steel wire is fed from a supply spool through a pulley and tension control unit to the wire guides. Multiple strands of a wire web are formed by winding the wire through the 500-3000 parallel grooves on the wire guides. The wire web is pulled by the torque applied by the main drive and slave rolls, while at the same time, $\mathrm{Si}$ ingots, glued to the holder, are fed against the moving wire web and sliced into hundreds/thousands of wafers each [5].

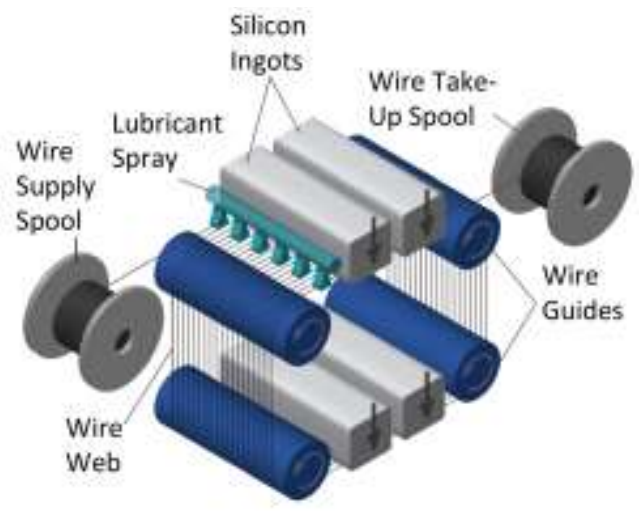

Figure 1. Schematic of multi-wire sawing of silicon ingots into wafers. [6]

The two main technologies used nowadays for Si wafering are multi-wire sawing with silicon carbide ( $\mathrm{SiC}$ ) slurry and with fixed diamond abrasives. In the first case, the cutting is achieved by $\mathrm{SiC}$ abrasive slurry which is supplied through nozzles over the wire web and carried by the wire into the sawing channel. The slurry is typically oil or polyethylene glycol (PEG) based, cutting speeds are usually between 10$20 \mathrm{~m} / \mathrm{s}$, ingot feed rate around $0.3-0.5 \mathrm{~mm} / \mathrm{min}$, which yields a total cutting time of 8-13 hours for a standard ingot size, and around $300-500 \mathrm{~km}$ of wire is used at once for a standard cut. The high consumption of wire in the slurry process is due to the damage done by the loose abrasives on the wire [7].

As for the multi-wire fixed abrasive sawing technology, the cut is done using a piano wire, which is impregnated or electroplated with diamond grits that serve as fixed cutting edges. The slurry is replaced here by a coolant fluid such as water, and the cutting work is based on the so-called pilgrimmode: the wire is set in motion in one direction for several hundred meters, stopped, and then set in motion in the opposite direction for a shorter length. As the cut direction and cutting speed of the wire change during the process (around 100 times in an usual wafering process), the resulting sawn surface identifies the effect of the reverse cutting direction in very thin lines (around $1 \mathrm{~mm}$ wide in this example). In comparison with the slurry technology, higher ingot feed rate can be achieved (>1 mm/min), and the cutting time is reduced to 2-3 hours. The fixed abrasive wire consumption is lower 
compared to the wire employed with slurry. The length of the wire is about $5 \mathrm{~km}$ and it can be used up to 4 times before it is worn out. Fixed abrasive wire sawing technology has rapidly gained industrial attention because of its potential of two to three times higher productivity and the potential to recycle the material removed from the kerf. The silicon chips that are cut away in the fixed abrasive process are clean and can be more easily recycled when compared to the slurry process [7]-[9].

Although both sawing techniques are currently used in the industry, a fundamental understanding of the underlying process is still missing for the diamond wire sawing. Consequently, optimization of the wire sawing process is carried out largely based on experience and trial and error [9]. Since the industrial wafering process is done reversing the cutting direction (pilgrim-mode), correlating the non-constant wire speed to the generated wafer surface can be not reliable and difficult to be performed. Moreover, as thousands meters of wire are used in one multi-wire cut, investigations on tool wear are usually done by sampling.

In order to investigate the wire sawing of mono-Si, a wafering test rig with a looped wire is proposed. Although some works about endless wire sawing of silicon can be found in the literature (see Table I), these works do not contemplate cutting speed $\mathrm{v}_{\mathrm{c}}>2 \mathrm{~m} / \mathrm{s}$ and wire diameter $\varnothing<500 \mu \mathrm{m}$ for mono-Si.

TABLE I. ENDLESS WIRE SAWS REFERED IN LITERATURE.

\begin{tabular}{lccc}
\multicolumn{1}{c}{ Author } & Material Cut & $\phi[\boldsymbol{\mu m}]$ & $\mathbf{V}_{\mathbf{c}}[\mathbf{m} / \mathbf{s}]$ \\
\hline Hardin et al. $[10]$ & Wood & 300 & $\leq 20$ \\
\hline Meng et al. [11]-[13] & $\begin{array}{l}\text { Granite, } \mathrm{Al}_{2} \mathrm{O}_{3} / \mathrm{TiC} \\
\text { and mono-Si }\end{array}$ & 500 & $\leq 20$ \\
\hline Gao et al. $[14],[15]$ & Granite & 800 & $\leq 20$ \\
\hline Subbiah et al. $[16]$ & Mono-Si & 140 & $\approx 2$
\end{tabular}

Industrial wafering machines are currently working with speeds that reach up to $30 \mathrm{~m} / \mathrm{s}$ and wires with outer diameter (OD) down to $80 \mu \mathrm{m}$ [17], which represent cutting conditions very different from those shown in Table 1. In all reported cases wires were firstly welded in looped-shape without any abrasives, and then coated with diamond grains in a self-made way.

An endless wire saw requires wires in looped shape to work. However, thin diamond wires as those used to slice silicon ingots for the PV and semiconductor industry, but in looped-shape, cannot be found in the market. Therefore, a device for joining wire-ends is proposed. The device must be capable of performing the butt-weld of wires with $\emptyset<500 \mu \mathrm{m}$ in looped-shape using diamond coated wires from the industry.

\section{Resistance Upset Welding Device}

The device was designed based on the Pahl \& Beitz methodology, in which the test rig function requirements are defined and multiple solutions for each function are proposed. By combining the principles of the solutions, different concepts were created. The best concept was chosen by evaluating the main requirements for the test rig, listed as follows:

- the wire ends must be put in contact with alignment deviation lower than $10 \%$ of wire diameter;

- $\quad$ electrical current must pass through the wire ends;

- controllable upsetting force responsible for pressing the wire ends together and forging them;

- it must be possible to remove the wire welded in looped shape from the device.

The resistance upset welding was chosen to be the welding method for the device. The upset welding (also called buttwelding), is a solid-state variation of resistance welding. Rather than fusion (melting followed by coalescence), the primary method of creating a joint during upset welding is by forging ("upsetting") with resistance heating to improve plastic deformation during upsetting. The process produces coalescence over the entire area of facing surfaces or progressively along the butt joint by heat caused by the resistance to the flow of the current through the area where those surfaces are in contact [18]. The wire ends are clamped in the welding device, current is passed through the joint heating up the abutting surfaces, and force in the direction of the wire is then applied to bring the parts tightly together, Fig. 2 .

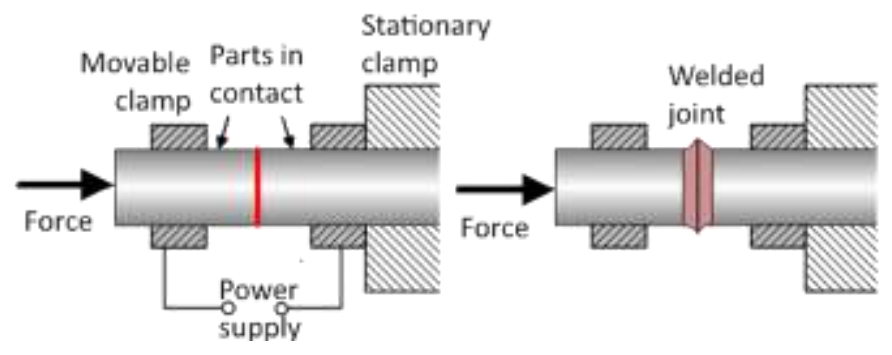

Figure 2. The upset welding principle. [19]

\section{A. Conceptual Design}

The conceptual solution proposed for the upset device is shown in Fig. 3 and Fig. 4.

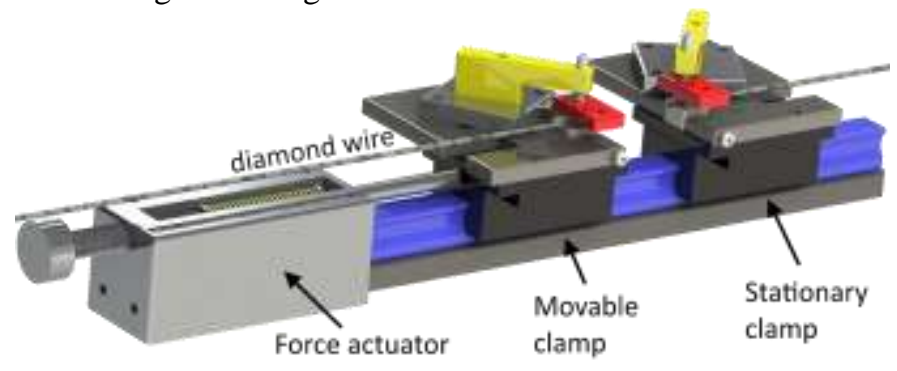

Figure 3. Conceptual solution for the upset welding device (3D view).

The device is composed by a linear guide rail with two carriages on its top. On each carriage, clamps that provide the necessary electric contact hold the wire ends on insulated grooved ceramic supports. A spring provides controlled force to the movable carriage, pressing the wire ends together. 


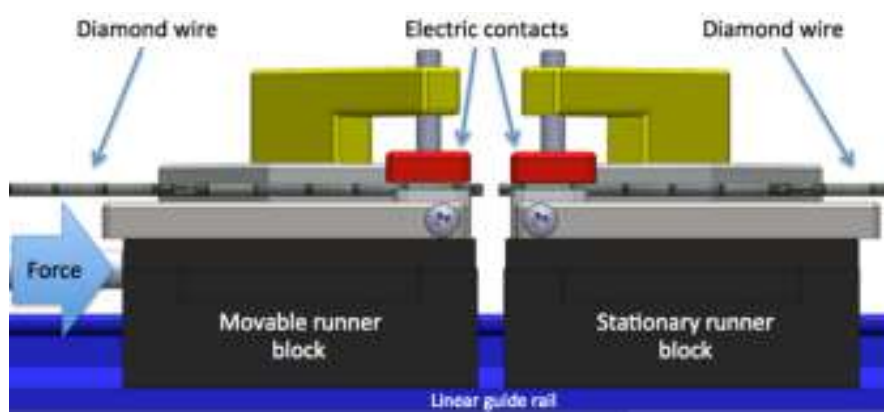

Figure 4. Conceptual design of the upset welding device (2D view).

\section{B. Upset Welding Device Features}

Each wire end is fixed on the top of a ceramic support on a carriage by a clamp. The wire clamp is composed by: clamping screw (1), ball bearing (2), adjusting rod (3), aluminum clamping plate (4) and the electric contact (5), Fig. 5 .

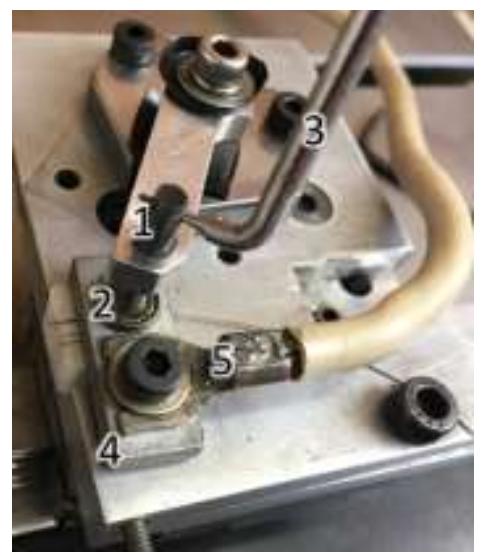

Figure 5. Wire clamp.

Grooved aluminum oxide inserts attached to the carriage serve as support base for the diamond wires. The alignment of the wire ends is guaranteed by the grooves that were shaped simultaneously on the top surface of both insulating inserts with the size of the diamond wires. The grooves on top of the supporting inserts resist to abrasion and withhold their dimensions for many welds. The low heat transmission of aluminum oxide reduces the required welding power to heat up the nucleus of the diamond wire.

The grooves of the ceramic suports were done under a microscope to guaranty perfect alignment and permit to bring the wire ends together with respective alignment in a very narrow range. Grooves with different geometries were shaped on the aluminum oxide inserts using diamond wires as shaping tools, so that wires with different OD can be welded, Fig. 6 .

In Fig. 7 it is shown the upset welding device with a diamond wire clamped forming a looped-shape. The welding procedure is done as follows: after preparing and cleaning the two wire ends, they are positioned on collinear grooves with the corresponding shape. The protusion of the wire ends on the border of the cermic inserts is controlled by a spacer.
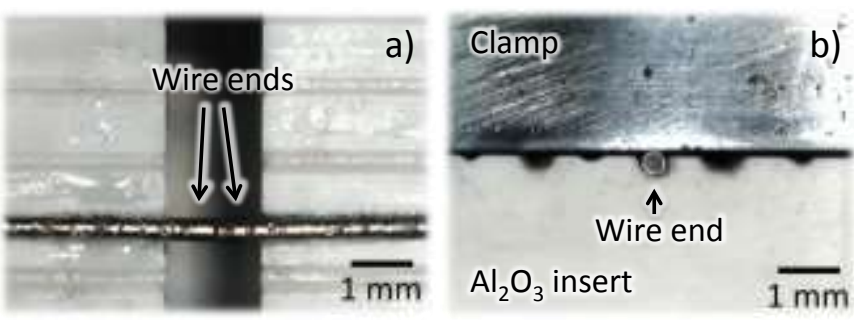

Figure 6. Grooves on aluminum oxide inserts: a) top view, b) front view.

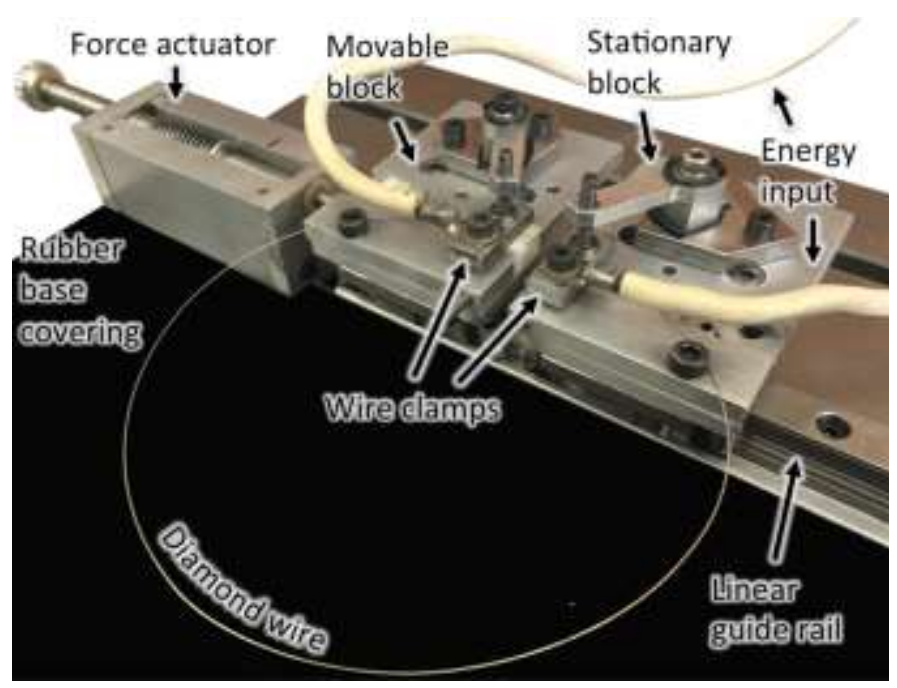

Figure 7. Upset welding device.

The wires are then fixed by the wire clamps and put in mechanical contact by moving the carriages. Electric current is turned on and it flows through the contacted wire ends interface. Heat is generated by Joule effect. The superheated core of the wire ends is plastically deformed by the upsetting counter force, creating the welded joint. At the joint, the excess of material pressed out forms a burr around the wire.

The wire core is cold-drawn ASTM A 228 steel. To increase the wire ductility, after the weld is completed, a tempering procedure is done by passing a lower electrical current through the joint, which tempers the material. After the tempering procedure, the burr pressed out at the joint is carefully sanded away so that the joint diameter becomes smaller than the outer diameter of the diamond wire.

\section{Power Supply System}

The energy source of the upset welding device is composed basically by the user interface, power supply circuits and a control circuit (see Fig. 8). The welding parameters are shown in the display of the user interface, and can be configured by the user. The user interface also shows the stage of the welding process using 4 different indication LEDs and alert sounds. Based on the inputs given in the user interface, the control circuit regulates the AC power supply. A DC power supply is responsible for providing energy to the control circuit. 
Proc. of the Fifth Intl. Conf. Advances in Civil, Structural and Mechanical Engineering - CSM 2017 Copyright (C) Institute of Research Engineers and Doctors, USA .All rights reserved.

ISBN: 978-1-63248-132-0 doi: 10.15224/ 978-1-63248-132-0-38

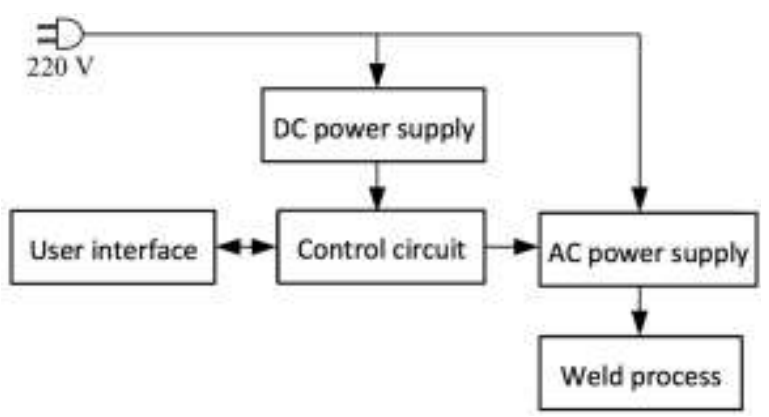

Figure 8. Power supply system.

The AC power supply reduces the input voltage of the system (220 V in this case) to a safe range for the welding process. Output commands from the control circuit will define the voltage and the current that will be provided to the weld process. Electric current values $\mathrm{C} 1, \mathrm{C} 2$, and time steps $\mathrm{T} 1, \mathrm{~T} 2$, $\mathrm{T} 3$ and T4 can be configured in the user interface as welding parameters.

The current over the time in the welding process is represented in Fig. 9. The configured value $T 1$ defines the time for the electric current $\mathrm{C} 1$ that performs the actual weld of the wire ends. Between $T 1$ and $T 2$, the current is linearly reduced to a lower current $C 2$ and kept constant until $T 3$. From $T 3$ to $T 4$ the current is linearly reduced to zero.

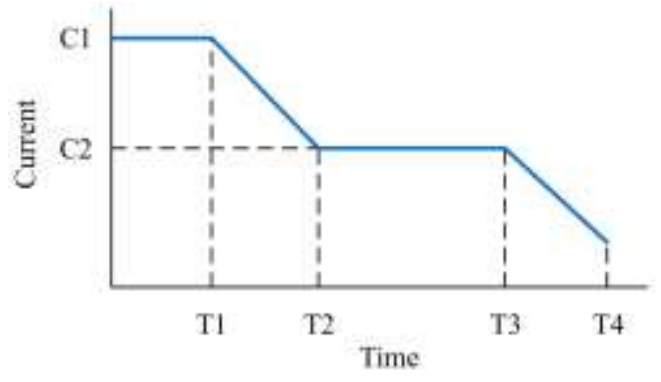

Figure 9. Configured voltage during the welding process.

The stepwise reduction of the current works as a tempering procedure to the welded material, which increases the material ductility. Otherwise, by dropping $C 1$ to zero after $T 1$, the temperature of the welded joint is reduced too fast, which makes the joint fragile.

\section{Iv. Upset Welding Experiments and Results}

The upset welding device was validated by welding diamond wires with $\mathrm{OD}=200 \mu \mathrm{m}$ and $350 \mu \mathrm{m}$. The diamond wires were placed in the corresponding grooves under a digital microscope and clamped with a protrusion length around 1.5 times the respective wire OD over the edge of the ceramic inserts. The carriages were than positioned together to guaranty electric contact between the wire ends. One carriage is fixed and the second one is preloaded with an axial spring force sufficient to not bend the wire ends. The electric current is turned on. The wire turns red hot and the spring force moves the movable carriage against the stationary one. At this moment the electric power supply reduces the current to the preset value, and then to zero, concluding the weld.

Aiming to find the optimized welding parameters to be configured in the user interface, tests were conducted with different input values. The joints welded with different sets of input parameters were analyzed in terms of joint tensile strength, alignment and volume of pressed out material. The best sets were then found for both wires, OD $=200 \mu \mathrm{m}$ and $350 \mu \mathrm{m}$. In order to know the actual values of current and voltage of the welding process, measurements were performed between the wire clamps during the welding process. In Table II are presented the time steps $\mathrm{T}$, the average value of the root mean square signal measured for electric current $C_{R M S}$ and tension $\mathrm{U}_{\mathrm{RMS}}$ for both wires.

TABLE II. WELDING PARAMETERS MEASURED BETWEEN THE WIRE CLAMPS.

$$
\mathrm{OD}=\mathbf{2 0 0} \mu \mathrm{m} \quad \mathrm{OD}=\mathbf{3 5 0} \mu \mathrm{m}
$$

\begin{tabular}{ccc}
\hline $\boldsymbol{C} \boldsymbol{1}_{\boldsymbol{R M S}}[\boldsymbol{A}]$ & 20 & 25 \\
$\boldsymbol{C} \boldsymbol{2}_{\boldsymbol{R M S}}[\boldsymbol{A}]$ & 12 & 25 \\
$\boldsymbol{U} \boldsymbol{1}_{\boldsymbol{R} M S}[\boldsymbol{V}]$ & 0.6 & 0,7 \\
$\boldsymbol{U} \boldsymbol{2}_{\boldsymbol{R M S}}[\boldsymbol{V}]$ & 0.2 & 0,5 \\
$\boldsymbol{T 1}[\boldsymbol{s}]$ & 0.2 & 1 \\
$\boldsymbol{T 2}[\boldsymbol{s}]$ & 1.2 & 2 \\
$\boldsymbol{T 3}[\boldsymbol{s}]$ & 61.2 & 32 \\
$\boldsymbol{T 4}[\boldsymbol{s}]$ & 121.2 & 62 \\
\hline
\end{tabular}

The procedure of aligning the wire in the grooves of the ceramic inserts showed to be an adequate solution to guaranty a proper alignment, Fig. 10.

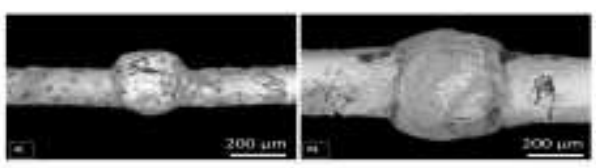

Figure 10. Welded joint of looped diamond wires: a) $\varnothing=200 \mu \mathrm{m}, \mathrm{b}) \emptyset=$ $350 \mu \mathrm{m}$.

Metallography analyses were performed on the longitudinal cross-section of welded joints of $200 \mu \mathrm{m}$ and $350 \mu \mathrm{m}$ OD wires. The length of the indicated heat affected zones (HAZ) corresponds approximately to the protrusion of each wire end, which gives the distance between the aluminum clamps. The grain structure outside the HAZ is fine and elongated in the wire axis' direction. However, inside the HAZ the grain structure is coarse, which indicates grain recrystallization due to the tempering procedure achieved by the stepwise reduction of the current. Energy dispersive spectroscopy (EDS) analysis indicated that the core of the wire is steel; the covering layer and the bright region of pressed out material are nickel. 


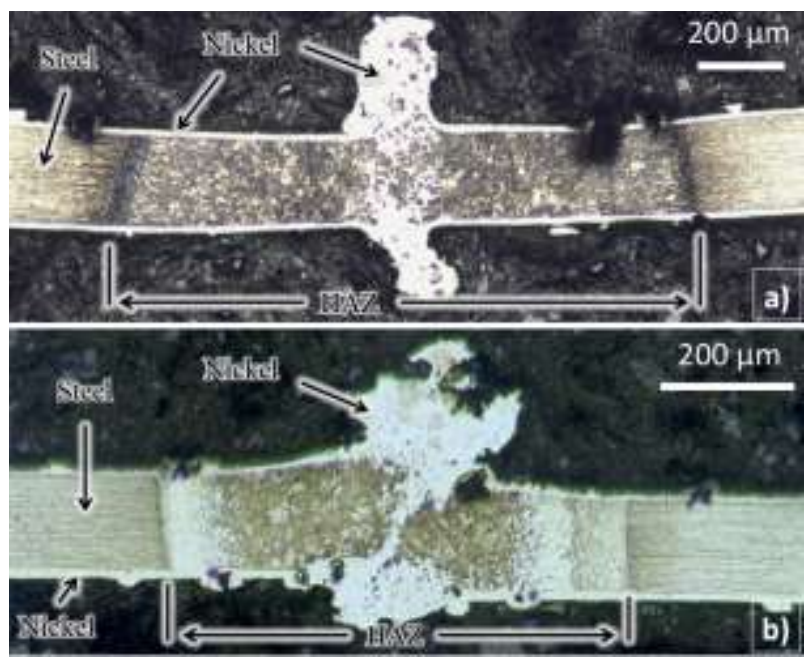

Figure 11. Metalography of welded joints: a) $\varnothing=200 \mu \mathrm{m}, \mathrm{b}) \emptyset=350 \mu \mathrm{m}$.

The welded joints presented considerable tensile strength under tension tests. Wires with $\mathrm{OD}=350 \mu \mathrm{m}$ exhibited tensile strength of $105 \mathrm{~N}$, and welded joints of wires with $\mathrm{OD}=200 \mu \mathrm{m}$ presented tensile strength of $33 \mathrm{~N}$. These values are about $50 \%$ higher than the required tensile stress applied on a diamond wire on multi-wire Si sawing equipment. These results were later on verified in their final application: the endless wire saw test rig. Looped wires welded by this device were winded around two pulleys and set in motion to cut mono-Si workpieces. As result, the looped wires presented sufficient resistance to the mechanical stresses related to the wire sawing process. Experiments on tool life could also be carried out with the looped diamond wires.

\section{v. Summary and Outlook}

A resistance butt-welding device was designed and built. The device performs the weld by application of current in different levels so that the material of the joint is tempered. The resulting welded joints exhibited good alignment and sufficient tensile strength. The next steps for the research on wire sawing of silicon will be to perform sawing experiments for investigations on wire wear, cutting forces and surface integrity of mono-Si workpieces.

\section{Acknowledgments}

The authors would like to thank Saint-Gobain Abrasives and the National Counsel of Technological and Scientific Development (CNPq - Brazil) for their support.

\section{References}

[1] H. J. Möller, C. Funke, M. Rinio, and S. Scholz, "Multicrystalline silicon for solar cells," Thin Solid Films, vol. 487, no. 1-2, pp. 179187, 2005.

[2] T. L. Jester, "Crystalline silicon manufacturing progress," Prog. Photovoltaics Res. Appl., vol. 10, no. 2, pp. 99-106, 2002.

[3] C. del Cañizo, G. del Coso, and W. C. Sinke, "Crystalline Silicon
Solar Module Technology: Towards the 1s Per Watt-Peak Goal," Prog. Photovoltaics Res. Appl., vol. 17, pp. 199-209, 2009.

H. A. Aulich, S. F. W., and A. O., "Large scale crystallisation and wafer production-the way to 2020," 25th Eur. Photovolt. Sol. Energy Conf. Exhib. World Conf. Photovolt. Energy Convers., 2010. H. Wu, "Wire sawing technology: A state-of-the-art review," Precis. Eng., vol. 43, pp. 1-9, 2016.

R. Automation, "Automation Control for Wafer Slicing Equipment," OEM-AP061A-EN-P. USA, 2009.

H. J. Möller, "Wafering of Silicon," Semicond. Semimetals, vol. 92, pp. 63-109, 2015.

H. J. Möller, "Wafering of silicon crystals," Phys. Status Solidi aApplications Mater. Sci., vol. 203, no. 4, pp. 659-669, 2006.

H. Wu, "Fundamental Investigations of Cutting of Silicon for Photovoltaic Applications," Georgia Institute of Technology, 2012.

C. W. Hardin, "Fixed Abrasive Diamond Wire Saw Slicing of Single Crystal SiC Wafers and Wood," North Carolina State University, 2003.

[11] J. F. Meng, P. Q. Ge, and J. F. Li, "The surface quality of monocrystalline silicon cutting using fixed abrasive diamond endless wire saw," Int. J. Comput. Appl. Technol., vol. 29, no. 2/3/4, p. 208, 2007.

[12] J. F. Meng, J. F. Li, P. Q. Ge, and R. Zhou, "Research on Endless Wire Saw Cutting of Al2O3/TiC Ceramics," Key Eng. Mater., vol. 315-316, pp. 571-574, 2006.

[13] J. F. Meng, J. F. Li, P. Q. Ge, and W. Gao, "Removal Mechanism in Wire-Sawing of Hard-Brittle Material," Mater. Sci. Forum, vol. 471-472, pp. 192-195, 2004.

[14] W. Gao, B. J. Ma, T. K. Cao, and Z. C. Liu, "Researching and Manufacturing of Endless Diamond Wire Saws and the Cutting Experiment," Key Eng. Mater., vol. 359-360, pp. 445-449, 2008.

[15] W. Gao, J. T. Zhang, and J. Y. Duan, "Study on the Wear Topography of Diamond Endless Wire Saw when Cutting Granite," Key Eng. Mater., vol. 487, pp. 361-365, 2011.

[16] S. Subbiah, K. Saptaji, and H. Zarepour, "A Study of Linear Vibration-Assisted Scratching on Silicon and its Impact on the Diamond Wire Wafering Process," Eur. Photovolt. Sol. energy Conf. Exhib., pp. 1483-1486, 2013.

[17] M. B. G. AG, "MB Wire Saw DW 288 Series 3.” 2016.

[18] T. J. . Lienert, S. S. Babu, T. A. . Siewert, and V. L. Acoff, ASM Handbook, vol. 06A. 2011.

[19] D. Kopeliovich, "Substech Substances \& Technology," 2012. [Online]. Available: http://www.substech.com/. [Accessed: 25-Apr2017].

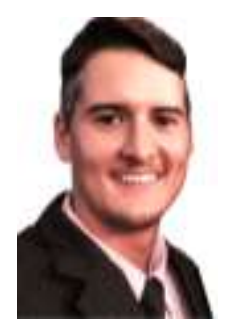

About Author:

Ricardo Knoblauch has been investigating the diamnond wire sawing of monocrystalline silicon since 2012. From 2012 to 2015 his research was carried out at the Institute of Machine Tools and Manufacturing - Swiss Federal Institute of Technology, ETHZ - Switzerland. Currently he is $\mathrm{PhD}$ candidate and research assistant at the Precision Engineering Laboratory at the Universidade Federal de Santa Catarina, UFSC - Brazil. 